\title{
The effect of cigarette smoking on the severity of pain, swelling and trismus after the surgical extraction of impacted mandibular third molar
}

\author{
Ra'ed-M. Al-Delayme ${ }^{1,2}$ \\ ${ }^{1}$ B.D.S, S.OMFS.S, C.A.B.OMFS, M.F.D. R.C.S. I., M.O.M.S. R.C.P.S .G, F.F.D (OSOM) R.C.S. I. Senior Lecturer at oral and \\ Maxillofacial Surgery Dept., Faculty of Dentistry, AL-Yarmuk University College, Baghdad, Iraq \\ ${ }^{2}$ B.D.S, S.OMFS.S, C.A.B.OMFS, M.F.D. R.C.S. I., M.O.M.S. R.C.P.S .G, F.F.D (OSOM) R.C.S. I. Senior Specialist at oral and \\ Maxillofacial Surgery Dept., AL-Yarmuk Teaching Hospital, Baghdad, Iraq
}

Correspondence:

Oral and Maxillofacial Surgery Department

Dentistry Department

AL-Yarmuk University College

Baghdad, Iraq

raedmaxfax@yahoo.com

Received: 28/08/2012

Accepted: 24/05/2013

\begin{abstract}
Al-Delayme RM. The effect of cigarette smoking on the severity of pain, swelling and trismus after the surgical extraction of impacted mandibular third molar. J Clin Exp Dent. 2013;5(3):e117-21.

http://www.medicinaoral.com/odo/volumenes/v5i3/jcedv5i3p117.pdf
\end{abstract}

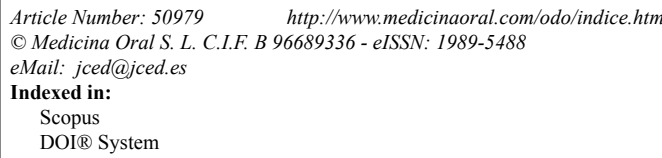

DOI System

\begin{abstract}
Objective: The study objective was to investigate the effect of cigarette smoking on the severity of pain, swelling and trismus on male after the surgical removal of impacted lower third molar.

Material and Methods: This prospective comparative study was conducted for 150 male in two groups of patients, smokers and non-smokers. Each group consisted of 75 patients; smoking patient were the ones who smoke more than twenty cigarettes per day for more than one year of continuous smoking. Postoperative pain was evaluated using a visual analog scale (VAS) and the degree of swelling was evaluated through facial reference points' variation. The presence of trismus was analyzed through measurement of the interincisal distance (IID).

Result: Clinical and radiographic examinations were carried out. Data regarding the age, gender, angulations type, depth and width of impactions were evaluated and analyzed

The severity of pain, swelling and trismus on the 1st, 2nd, 5th and 7thday postoperatively was estimated. In both groups the pain and trismus were reported to be in peak level during the first post-operative day while post-operative swelling reaches its peak level in the second postoperative day.

Conclusion: Cigarettes smoking do not have any significant relationship with the severity of pain, swelling and trismus after surgical removal of lower third molar on male gender.
\end{abstract}

Key words: Cigarettes smoking, pain, swelling, trismus, impacted lower third molars. 


\section{Introduction}

It has been scientifically and medically proven that smoking is the cause of a verity of different crucial, deadly illnesses and diseases $(1,2)$ among them tooth decay (3-6). In addition, the tobacco use is known to impair wound healing $(7)$.Research $(8,9)$ has shown that smokers are more likely to suffer complications during and following general surgery.

The surgical removal of impacted lower third molar is the daily procedure that is performed by oral and maxillofacial surgeons (10) which involve a lot of post-operative complications (11), the most common postoperative signs and symptoms of complications are pain, swelling and trismus (12) that affected to a certain degree by severity of many factors and variables (13).

Although many articles (14-17) have been published on the effect of smoking on dry socket, smoking as a risk factor for the pain, swelling and trismus is still a debatable issue.

To the knowledge of the author there are no studies which discuss the effect of smoking on pain, swelling and trismus after the surgical removal of impacted lower third molar.

Thus, this study aims to investigate the clinical significance of smoking on the severity of pain, swelling and trismus in different postoperative times.

\section{Material and Methods}

- Study Design and Sample:

This prospective cohort study was obtained from the patients referred for management of impacted third molars to the Oral and Maxillofacial Surgery department, College of Dentistry, SIUST University, from November 1, 2008 to October1, 2010. Ethics Committee of the University has approved this research protocol. A total of 164 participants (healthy men) were selected. All the patients have been informed by an informed consent.

The inclusion criteria for these prospective studies were healthy men patients, without medication, older than 18 years, who completed the questionnaire and agreed to follow the postoperative instructions. Of the 164 patients, 9 were excluded from the study for not completing the questionnaire correctly, 3 for not following the postoperative instructions and 2 complain from post-operative dry socket.

Patients diagnosed with one impacted mandibular third molars that need surgical extraction under local anesthesia were included in this study. They were not given any preoperative medications. They were divided in two groups: smokers and non-smokers. The smoking group consisted of 75 patients who used to smoke more than twenty cigarettes per day for more than one year of continuous smoking and their ages range from 20-27 with the mean $24.56 \pm 2.97$ at the time of operation while nonsmoking group consisted of 75 patients who never smoked before with age range from 19-25 with the mean $22.48 \pm 3.12$ at the time of operation. All patients were routinely examined using conventional panoramic radiographs. The data relating to each patient in each group were recorded which included age, Winter's classification and Pell and Gregory classification for the position of the impacted mandibular third molars (18), in addition to the duration of surgical operation (Table 1).

- Surgical Procedure:

The surgical procedure was similar in all cases and was operated by the same oral surgeon, with the protocol that included using $1.8 \mathrm{~mL}$ of $2 \%$ lidocaine hydrochloride with 1:80,000 adrenaline solutions. The time of injection and the time of surgery started were noted; All teeth were removed from a buccal approach using triangular flap.

Table 1. Study variables grouped by smokers and nonsmokers.

\begin{tabular}{|c|c|c|c|}
\hline Variables & Smokers $(\mathrm{n}=75)$ & Nonsmokers $(\mathrm{n}=75)$ & P values* \\
\hline Age (years) & $24.56 \pm 2.97(20-27)$ & $22.48 \pm 3.12(16-25)$ & 0.97 \\
\hline \multicolumn{3}{|l|}{ Winter's classification } & \multirow{5}{*}{0.54} \\
\hline Mesioangular & $38(50.6)$ & $41(54.6)$ & \\
\hline Vertical & $19(21.3)$ & $17(22.6)$ & \\
\hline Horizontal & $11(14.6)$ & $13(17.4)$ & \\
\hline Distoangular & $7(9.3)$ & $4(5.3)$ & \\
\hline \multicolumn{3}{|c|}{ Pell and Gregory classification } & \\
\hline IA & $16(21.3)$ & $14(18.6)$ & \multirow{9}{*}{0.66} \\
\hline IB & $11(14.6)$ & $12(16)$ & \\
\hline $\mathrm{IC}$ & $5(6.6)$ & $6(8)$ & \\
\hline IIA & $12(16)$ & $14(18.6)$ & \\
\hline IIB & $18(24)$ & $15(20)$ & \\
\hline IIC & $6(8)$ & $7(9.3)$ & \\
\hline IIIA & $2(2.6)$ & $4(5.3)$ & \\
\hline IIIB & $3(4)$ & $2(2.6)$ & \\
\hline IIIC & $2(2.6)$ & $1(1.3)$ & \\
\hline Operation time (minutes) & $26.37 \pm 13.5(9-51)$ & $27.44 \pm 11.65(11-48)$ & 0.49 \\
\hline
\end{tabular}

* ANOVA analysis 
Bone surrounding the third molar was removed with a round bur in a hand piece using a copious amount of saline irrigation. In the majority of cases, the third molar was split using a tungsten fissure bur and a straight elevator as the routine technique. The tooth was divided with burs before elevation. The alveolus was inspected and curetted for granulation tissue followed by irrigation with saline. The flaps were sutured with a 4-0 silk suture. The time of completion the surgical procedure was noted. Postoperative instructions and prescribed drugs were explained to the patients, the smoking patient was instructed to stop smoking for first eight hours after the operation. For the first 5 postoperative days all patients were given antibiotics (amoxicillin $500 \mathrm{mg}$ every 8 hours), and acetaminophen $500 \mathrm{mg} 4$ times daily for 3 days postoperatively. And a mouth rinse $(0.2 \%$ chlorhexidinedigluconate) was started form the second day, every 12 hours for 5 days. The suture material was removed after one week. All surgical details were noted in a pre-made questionnaire. - Post-Surgical Assessment:

For each patient the severity of postoperative pain, swelling and trismus on the 1st, 2nd, 5th and 7thday postoperatively was estimated (Table 2). A single blind professional operator was different from the surgeon who performed the surgery, repeating each record three times on each patient before and after the operation. The average of measurements was then taken and recorded.

Postoperative pain was assessed by a $10 \mathrm{~mm}$ visual analogue scale(VAS) with the end points marked as "no pain" and "worst pain ever experienced". Absence of pain was scored as 0 . If pain was present the patient was asked to select a field from $1 \mathrm{~mm}$ to $10 \mathrm{~mm}$. For each patient, the appropriate score was recorded in the questionnaire by one operator.

Two distances were considered to evaluate the facial measurements of swelling, that is the distance from the corner of the mouth to the ear lobe and the outer canthus of the eye to the angle of the mandible measured by a thread which was then transferred to a ruler, the difference between the postoperative and preoperative measurements was calculated to measure the swelling area, it was $\left(\mathrm{cm}^{2}\right)$.
Trismus was assessed by measuring the differences in mouth opening (interincisal distance preoperatively and on post-surgery).The difference between the postoperative and preoperative measurements was calculated to measure the trismus $(\mathrm{mm})$.

- Statistical analysis :

Statistics were calculated using the SPSS for Windows (v. 13.0, SPSS Inc, Chicago, IL) statistical software package. A multivariate repeated measure ANOVA was used to describe changes in the three primary outcomes (swelling, trismus and pain) over time. The model included age, gender, ostectomy and surgery time (in minutes), class of tooth impaction, mandibular relationship, and occlusal plan as independent predictive variables .The cross table technique was applied for assessment of the variables (pain, swelling and trismus) of two groups: smokers and non-smokers. Probability less than 0.05 was considered statistically significant.

\section{Results}

A total of 150 from 164 patients have included in the study analysis. The average duration of the surgery on the smoking group was $26.37 \pm 13.5$ minutes (range, 9-51 minutes); on the nonsmokers group, it was $27.44 \pm 11.65$ minutes with the range (11-48 minutes). The mesioangular impaction according to the Winter classification was the most common types of impaction in both groups 38 $(50.6 \%)$ in smokers and $41(54.6 \%)$ in nonsmoking patients while the IIB impaction type according to Pell and Gregory classification was the most common types of impaction in both groups $18(24 \%)$ in smokers and $15(20 \%)$ in nonsmoking patients. Both groups did not differ in age, position, or angulations.

Table 2 presents postoperative pain intensity, facial swelling and maximal mouth opening on post-operative days in both groups. In both groups the pain and trismus were reported to be most intense and in peak level during the first post-operative day while post-operative swelling reached its peak level in the second postoperative day. By the post-operative seven day, most of the patients restored their preoperative values in both groups.

Table 2. Smokers and nonsmoker's pain severity, swelling and trismus mean in different post-operative times.

\begin{tabular}{|c|c|c|c|c|c|c|c|c|}
\hline \multirow[t]{2}{*}{ Category } & \multicolumn{2}{|c|}{$\begin{array}{l}\text { 1stpost-operative } \\
\text { day }\end{array}$} & \multicolumn{2}{|c|}{ 2ndpost-operative day } & \multicolumn{2}{|c|}{ 5th post-operative day } & \multicolumn{2}{|c|}{ 7th post-operative day } \\
\hline & Smokers & Non & Smokers & Non & Smokers & Non & Smokers & Non \\
\hline $\begin{array}{ll}\text { VAS SCORE mean } \pm \\
\text { SD }(\mathrm{mm})\end{array}$ & $3.73 \pm 1.58$ & $3.73 \pm 1.62$ & $2.31 \pm 1.93$ & $2.2 \pm 1.49$ & $1.76 \pm 1.65$ & $1.72 \pm 1.44$ & $0.86 \pm 1.06$ & $0.91 \pm 1.11$ \\
\hline $\mathrm{p}$ & \multicolumn{2}{|l|}{0.326} & \multicolumn{2}{|l|}{0.203} & \multicolumn{2}{|l|}{0.432} & \multicolumn{2}{|l|}{0.532} \\
\hline $\begin{array}{l}\text { Swelling mean } \pm \text { SD } \\
(\mathrm{cm} 2)\end{array}$ & $9.24 \pm 11.12$ & $5.7 \pm 9.82$ & $37.6 \pm 27.61$ & $36.74 \pm 23.03$ & $3.96 \pm 5.54$ & $1.87 \pm 2.38$ & $0.44 \pm 1.02$ & $0.23 \pm 0.82$ \\
\hline $\mathrm{p}$ & \multicolumn{2}{|l|}{0.095} & \multicolumn{2}{|l|}{0.806} & \multicolumn{2}{|l|}{0.192} & \multicolumn{2}{|l|}{0.261} \\
\hline $\begin{array}{l}\text { Trismus } \\
\text { mean } \pm \text { SD }(\mathrm{mm})\end{array}$ & $2.42 \pm 4.51$ & $1.47 \pm 2.97$ & $2.07 \pm 4$ & $1.09 \pm 2.43$ & $0.37 \pm 0.76$ & $0.19 \pm 0.54$ & $0.09 \pm 0.43$ & $0.01 \pm 0.12$ \\
\hline $\mathrm{p}$ & \multicolumn{2}{|l|}{0.759} & \multicolumn{2}{|l|}{0.729} & \multicolumn{2}{|l|}{0.846} & \multicolumn{2}{|l|}{0.539} \\
\hline Total & 75 & 75 & 75 & 75 & 75 & 75 & 75 & 75 \\
\hline
\end{tabular}

Abbreviations: VAS: Visual analogue Scale; SD: stander deviation; $p$ :ANOVA analysis 
Although the severity of pain, swelling measurement and trismus of smoking group were more in all mean measurements than the nonsmoking group, at the end of the present study, the statistical analysis of resulting data confirms that there are no statistical significant differences between the two groups with regard to post-operative pain, swelling and trismus on males (Table 2).

\section{Discussion}

It is certain that there is a paucity of evidence that tobacco usage produces a significant degree of local and systemic negative effects on the morphological and functional aspects of the microcirculation (19) and deleterious effects on wound healing (7), and exerts a significant negative effect on the immune system (20).

It has been shown that chronic cigarette smoking regulates the expression of inflammatory process (21) and from that point the aim of this research was to present an evidence-based fact about the possibility of a significant association between tobacco smoking and the severity of pain, swelling and trismus which they originate from an inflammatory process initiated by surgical removal of impacted lower third molar (22).

The strengths points of this study were the consistency of only one surgeon and one gender that were males only. The other unique point is that the smoking group was with a history of smoking more than twenty cigarettes per day for more than one year of continuous smoking. Only one limitation is present in this study which is related to the study design, which did not include other types of tobacco smoking like cigar and shisha.

It has been reported that nicotine increases the pain threshold and tolerance rating of men, but has no effect on the pain rating of women (23). In the current study, this hypothesis could not be investigated because all the samples were males.

In all postoperative times, there was no statistic significant correlation between both groups in regarding the severity of pain registered on VAS and this observation also mentioned in two previous studied $(24,25)$.

The resulting data in all postoperative times also showed that cigarette smoking did not have any significant importance on the postoperative swelling and trismus and this finding came in line with other studies $(16,25,26)$ ,except for the study advanced by Grossi et al. study (15) which confirmed that tobacco use is a risk factor for trismus.

Studies have shown that pain, swelling and trismus following lower third molar removal are influenced by various factors other than smoking such as the difficulty of the surgical procedure involved (27) and the operation duration (28).

According to the findings demonstrated in the present research, it can be observed that cigarette smoking does not seem to have any statistically significant relationship on the severity of pain, swelling and trismus after surgical removal of lower third molar on males.

Further trials need to be conducted with using larger sample sizes from both gender and other types of tobacco smoking, such as cigar and shish, need to be conducted.

\section{References}

1. Wald NJ, Hackshaw AK. Cigarette smoking: an epidemiological overview. Br Med Bull. 1996;52:3-11.

2. Doll R, Peto R, Boreham J, Sutherland I. Mortality in relation to smoking: 50 years' observations on male British doctors. BMJ. 2004;328:1519.

3. Soni S, Kaur J, Kumar A, Chakravarti N, Mathur M, Bahadur S, et al. Alterations of rb pathway components are frequent events in patients with oral epithelialdysplasia and predict clinical outcome in patients with squamous cell carcinoma. Oncology .2005;68:314-25.

4. Winn DM .Tobacco use and oral disease. J Dent Educ. 2001;65, 306-12.

5. Martinez-Canut P, Lorca A, Magán R. Smoking and periodontal disease severity. J Clin Periodontal. 1995;22:743-9.

6. Chuang SK, Wei LJ, Douglass CW, Dodson TB. Risk factors for dental implant failure: a strategy for the analysis of clustered failuretime observations. J Dent Res. 2002;81:572-7.

7. Sørensen LT, Hemmingsen U, Kallehave F, Wille-Jørgensen P, Kjaergaard J, Møller LN, et al. Risk factors for tissue and wound complications in gastrointestinal surgery. Ann Surg. 2005;241, 654-8.

8. Theadom A, Cropley M. Effects of preoperative smoking cessation on the incidence and risk of intraoperative and postoperative complications in adult smokers: a systematic review. Tob Control. 2006; 15:352-8.

9. Sadr Azodi O, Bellocco R, Eriksson K, Adami J. The impact of tobacco use and body mass index on the length of stay in hospital and the risk of post-operative complications among patients undergoing total hip replacement. J Bone Joint Surg Br. 2006:10:1316-20.

10. Adeyemo WL, Ogunlewe MO, Ladeinde AL, Abib GT, Gbotolorun OM, Olojede OC, et al. Prevalence and surgical morbidity of impacted mandibular third molar removal in the aging population: a retrospective study at the Lagos University Teaching Hospital. Afr J Med Med Sci. 2006;35:479-83.

11. Ruta DA, Bissias E, Ogston S, Ogden GR. Assessing health outcomes after extraction of third molars: the postoperative symptom severity (PoSSe) scale. Br J Oral Maxillofac Surg. 2000;38:480-7.

12. Bouloux GF, Steed MB, Perciaccante VJ. Complications of third molar surgery. Oral Maxillofac Surg Clin North Am. 2007;19:117-28, vii.

13. Bello SA, Adeyemo WL, Bamgbose BO, Obi EV, Adeyinka AA. Effect of age, impaction types and operative time on inflammatory tissue reactions following lower third molar surgery. Head Face Med. 2011;7:8.

14. Nusair YM, Younis MH. Prevalence, clinical picture, and risk factors of dry socket in a Jordanian dental teaching center. J Contemp Dent Pract. 2007;8:53-63.

15. Grossi GB, Maiorana C, Garramone RA, Borgonovo A, Creminelli L, Santoro F. Assessing postoperative discomfort after third molar surgery. A prospective study. J Oral Maxillofac Surg. 2007;65:901-17.

16. Baqain ZH, Karaky AA, Sawair F, Khraisat A, Duaibis R, Rajab LD. Frequency estimates and risk factors for postoperative morbidity after third molar removal: a prospective cohort study. J Oral Maxillofac Surg. 2008;66:2276-83.Erratum in: J Oral Maxillofac Surg. 2009;67:706.

17. Quek SL, Tay CK, Tay KH, Toh SL, Lim KC. Pattern of third molar impaction in a Singapore Chinese population: a retrospective radiographic survey. Int J Oral Maxillofacial Surg. 2003;32:548-52. 
18. Monaco G, Montevecchi M, Bonetti GA, Gatto MR, Checchi L. Reliability of panoramic radiography in evaluating the topographic relationship between the mandibular canal and impacted third molars. J Am Dent Assoc. 2004;135:312-8.

19. Lehr HA. Microcirculatory dysfunction induced by cigarette smoking. Microcirculation. 2000;7:367-84.

20. Sørensen LT, Nielsen HB, Kharazmi A, Gottrup F. Effect of smoking and abstention on oxidative burst and reactivity of neutrophils and monocytes. Surgery. 2004;136:1047-53.

21. Meisel P, Siegemund A, Dombrowa S, Sawaf H, Fanghaenel J, Kocher T. Smoking and polymorphisms of the interleukin-1 gene cluster (IL- 1alpha, IL-1beta, and IL-1RN) in patients with periodontal disease. J Periodontol. 2002;73:27-32.

22. Garip H, Satılmış T, Dergin G, Uğurlu F, Göker K. Effects of midazolam/low-dose ketamine conscious intravenous sedation on pain, swelling, and trismus after surgical extraction of third molars. J Oral Maxillofac Surg. 2011;69:1023-30.

23. Grossi SG, Zambon J, Machtei EE, Schifferle R, Andreana S, Genco RJ, et al. Effects of smoking and smoking cessation on healing after mechanical periodontal therapy. J Am Dent Assoc. 1997;128:599607.

24. Pandurić DG, Brozović J, Susić M, Katanec D, Bego K, Kobler P. Assessing health-related quality of life outcomes after the surgical removal of a mandibular third molar. Coll Antropol. 2009;33:437-47. 25. López-Carriches C, Gómez-Font R, Martínez-González JM, Donado-Rodríguez M. Influence of smoking upon the postoperative course of lower third molar surgery. Med Oral Patol Oral Cir Bucal 2006;11:E56-60

26. Bui CH, Seldin EB, Dodson TB. Types, frequencies, and risk factors for complications after third molar extraction. J Oral Maxillofac Surg. 2003;61:1379-89.

27. Jerjes W, El-Maaytah M, Swinson B, Banu B, Upile T, D'Sa S, et al. Experience versus complication rate in third molar surgery. Head Face Med. 2006;2:14.

28. Blondeau F, Daniel NG. Extraction of impacted mandibular third molars: postoperative complications and their risk factors. J Can Dent Assoc. 2007;73:325.

\section{Conflict of Interest}

The authors declare that there are no conflicts of interest that could influence their work. 